\title{
Development and Application of a Wide Dynamic Range and High Resolution Atmospheric Aerosol Water-Based Supersaturation Condensation Growth Measurement System
}

\author{
Jiejie Bian ${ }^{1,2}$, Huaqiao Gui ${ }^{1,3, *}$, Xiuli Wei ${ }^{1}$, Tongzhu Yu ${ }^{1}$, Zhibo Xie ${ }^{3}$, Jie Wang ${ }^{1}$ and Jianguo Liu $1,2,3, * \mathbb{D}$ \\ 1 Key Laboratory of Environmental Optics and Technology, Anhui Institute of Optics and Fine Mechanics, \\ HFIPS, Chinese Academy of Sciences, Hefei 230031, China; jjbian@aiofm.ac.cn (J.B.); \\ xlwei@aiofm.ac.cn (X.W.); tzyu@aiofm.ac.cn (T.Y.); wangiie@aiofm.ac.cn (J.W.) \\ 2 University of Science and Technology of China, Hefei 230026, China \\ 3 CAS Center for Excellence in Regional Atmospheric Environment, Institute of Urban Environment, Chinese \\ Academy of Sciences, Xiamen 361021, China; zbxie@iue.ac.cn \\ * Correspondence: hqgui@aiofm.ac.cn (H.G.); jgliu@aiofm.ac.cn or zhous@hfcas.ac.cn (J.L.)
}

\section{check for} updates

Citation: Bian, J.; Gui, H.; Wei, X.; Yu, T.; Xie, Z.; Wang, J.; Liu, J. Development and Application of a Wide Dynamic Range and High Resolution Atmospheric Aerosol Water-Based Supersaturation Condensation Growth Measurement System. Atmosphere 2021, 12, 558. https://doi.org/10.3390/atmos12050558

Academic Editors: Yongming Han, Nanjun Chen and Merja Tölle

Received: 9 March 2021

Accepted: 21 April 2021

Published: 26 April 2021

Publisher's Note: MDPI stays neutral with regard to jurisdictional claims in published maps and institutional affiliations.

Copyright: (c) 2021 by the authors. Licensee MDPI, Basel, Switzerland. This article is an open access article distributed under the terms and conditions of the Creative Commons Attribution (CC BY) license (https:/ / creativecommons.org/licenses/by/ $4.0 /)$.

\begin{abstract}
The supersaturated condensation of atmospheric aerosol is important in the study of mechanisms of cloud condensation and even heavy air pollution. The existing technology cannot realize accurate dynamic control of wide range supersaturation, so it is difficult to study condensation growth characteristics of nanoparticles through different levels of supersaturation. Here, a supersaturated condensation growth measurement system with three-stage microscope pipes was developed. The resolution of supersaturated condensation system is 0.14 , within the range of 0.92 to 2.33 after calibration. Stabilization time is only about $80 \mathrm{~s}$ for saturation range $0.92-1.01$, which helps to control saturation rapidly, and the control deviation of saturation is no more than 0.06 . Measurement of different supersaturated condensation growth control conditions showed that, the particle size increased significantly compared with hygroscopic growth at high humidity. For single-component particles, the increase in size increased to a similar size at the same saturation, with a difference within $7.4 \%$. The increase in size for ammonium sulfate (AS) increased by $13.4-30.2 \%$ relative to that of glucose. For the mixed-component, the increase in size decreased about $15.9-25.0 \%$ with the increase of the glucose. Because the glucose coating on the surface of AS have hindered particle growth. This also shows that atmospheric ultrafine particles, especially inorganic salt particles, will rapidly grow into larger particles under supersaturated conditions such as increased environmental humidity, thus having some impact on environmental pollution and climate change.
\end{abstract}

Keywords: condensation growth control system; calibration saturation; wide dynamic range; growth performance

\section{Introduction}

During atmospheric pollution formation, visibility degrades sharply and is often accompanied by haze [1,2]. The activation and subsequent growth of ultrafine particles play important roles in air pollution and climate [3-5]. In the tropical rainforest region, ultrafine particles can be quickly activated and transformed to cloud droplets, and these can potentially contribute to the formation of cloud condensation nuclei [6].

Nano-scale particles growth to several micrometers usually occurs in a region of supersaturated vapor by condensing working fluid onto particles; therefore, nanoparticles can be detected by optical means [7-10]. The method of condensation growth is used to measure the particle number concentration of atmospheric aerosol and vehicle emissions and collect the particulate matter through supersaturation growth. Condensation processes are crucial to provide successful mitigation and adaptation measures and avoid severe negative impacts in a climate change era [11,12]. Furthermore, the condensation vapor 
is divided into water-based and alcohol-based. Alcohol-based vapor makes the aerosol grow to a larger size but usually has low toxicity. Currently, existing instruments using the supersaturation method include cloud condensation nuclei counters (CCNCs) and condensation particle counters (CPCs). CCNCs are applied to measure the cloud condensation nuclei $(\mathrm{CCN})$, and it requires a minimum water vapor supersaturation to convert into cloud droplets. The minimum supersaturation at which $\mathrm{CCN}$ can be measured in static diffusion chambers is higher than $0.2 \%$ because of the insufficient time for droplet growth, and this is not sufficiently low to match the supersaturation levels found in some marine stratus clouds [13]. To overcome some of the limitations of the static thermal-gradient chamber, several variations of the continuous-flow parallel plate thermal diffusion chamber have been developed $[14,15]$. The continuous sample flow eliminates batch sampling; however, this approach is limited to supersaturations larger than $0.1 \%$ because of the long growth times and diffusive and phoretic forces. For commercial CPCs, there are two primary types, the laminar and the mixed type. The condensation growth control system of the laminar type CPC comprises a saturator and a condenser. Sufficient heat input and residence time of working fluid enable the saturation in the saturator and the vapor is carried by the carrier gas to the condenser, where the vapor achieves a supersaturation state as a result of cooling (alcohol-based CPC). In the mixing type, a hot saturated flow is mixed with a cooler sample [16]. The mixing type CPC can be used to detect sub-3-nm ultrafine particles in atmospheric studies [17].

Currently, some applications have put forward new demands for particle growth control system, which require a wide dynamic range. For instance, particle growth at 96$101 \%$ Relative Humidity (RH) and the particle growth at different saturations, especially the particles less than $2.5 \mathrm{~nm}$ (saturation required is higher than 2.2 for its activation and growth) $[18,19]$. Hygroscopic growth measurement system is applied on the hygroscopic growth characteristic of aerosol particle size (atmospheric particles and laboratory study), and the maximum $\mathrm{RH}$ is usually reach around 95\% [20-22]. The main drawback of this system is that it is hard to reach high RH such as $96-100 \%$. In recent years, the TSI Model 3788 condensation particle counter has been developed and broadly applied in particle number concentration measurement. However, the saturation cannot be controlled dynamically and the detection limitation is $2.5 \mathrm{~nm}[23,24]$. In addition, its optical detection module must be heated to a temperature similar with growth module and their heating time more than $10 \mathrm{~min}$. Therefore, the development of a wide dynamic range (0.95-2.2) supersaturation condensation growth control system is an important requirement for particles growth study.

The aim of our study was to develop a condensation growth system with adjustable supersaturation levels for measuring growth characteristic of standard particle and atmospheric aerosol. The calibration and characterization of key parameters were carried out, and the characteristics of monodisperse standard particles and atmospheric particles were examined under different saturation conditions.

\section{Materials and Methods}

\subsection{Description of Water-Based Supersaturated Condensation Growth Measurement System}

In order to realize the research of particles in the saturation range of 0.95-2.2 with different particle sizes and chemical components, a water-based supersaturated condensation growth measurement system was constructed. The design principle of the water-based supersaturation condensation growth system is based on the water vapor condensation, water vapor condensed on the particles when the sample gas with atmospheric particles through the supersaturated condensation growth measurement system, and water-based supersaturation condensation growth control unit provide a temperature gradient. Because the water vapor diffusion rate is higher than the gas heat transfer rate, the water vapor around the particles is supersaturated, causing water vapor to condense on the surface of the particles and promoting the particle size increase. The schematic diagram of the system is shown in Figure 1. The system consists of particle generation and selection unit, 
water-based supersaturated condensation growth control unit, and particle characteristic measurement unit. The core design uses condensation growth control unit, which can achieve the design goal and benefit to the measurement of the later stage. See Section 2.2 for the specific design and implementation. For particle generation and selection unit, polydisperse aerosol was generated and then was injected into dryer, charger, and differential mobility analyzers (DMA, model 3086 TSI, Shoreview, MN, USA) to obtain standard monodisperse particles. The monodisperse particles were diluted with filter air and then the mixed flow is divided into two road, one flow into condensation particle counter (CPC, model 3788 TSI, Shoreview, MN, USA) to record the concentration and other flow into condensation growth unit to study growth characteristic. Generally, monodisperse particles flow is $0.6 \mathrm{~L}$; the flow rate and concentration can be adjusted according to the need of the study. Humidity of mixed flow was recorded by a T/RH sensor (Rotronic HC2-S) before flow into saturation condensation growth control unit. Temperature control of condensation growth control unit by PID control was done to facilitate temperature control and temperature feedback; this is helpful to control saturation. At the same time, three peristaltic pumps (LIQUIPORT, KNF, Freiburg, Germany) were used to provide recycled water to three pipes of condensation growth control unit for better saturation control. The temperature can be controlled for the indoor temperature or based on our requirement. Particle characteristic measurement unit included aerodynamic particle sizer (APS, model 3321 TSI, Shoreview, MN, USA) and optical particle counter (OPC); the size distribution was recorded after growth in order to better study growth characteristic.

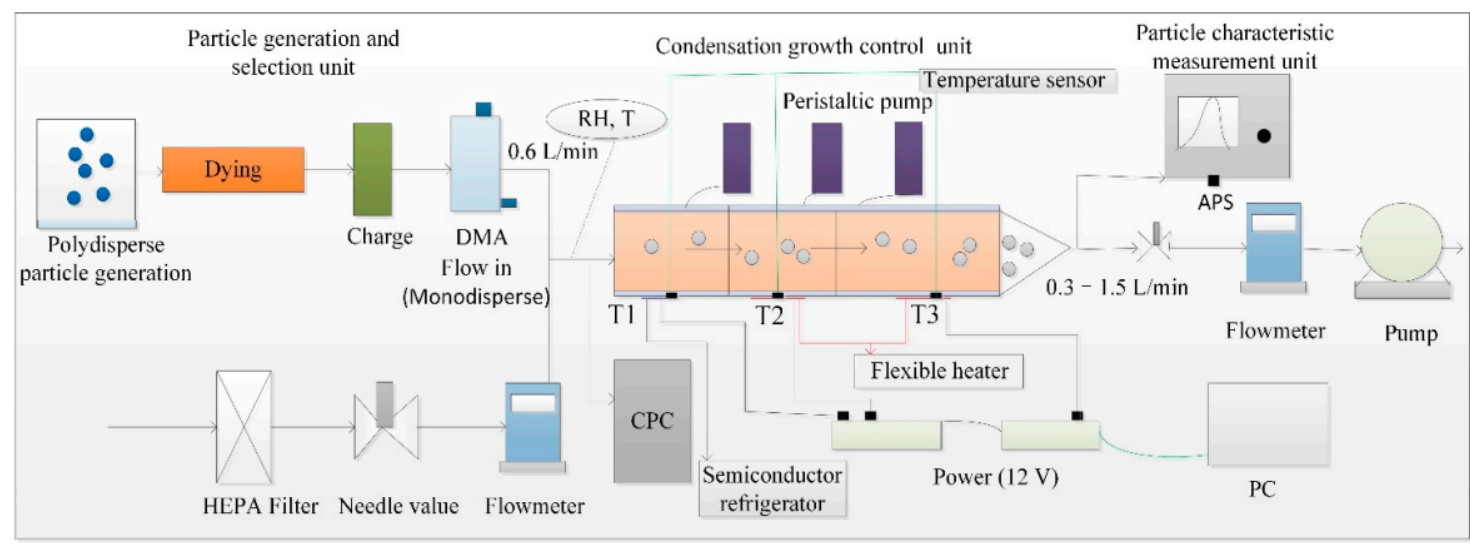

Figure 1. Schematic diagram of water-based supersaturated condensation growth measurement system.

\subsection{Description of Water-Based Supersaturation Control Unit}

A schematic diagram of the water-based supersaturated condensation growth control unit in this study is shown in Figure 2. The unit comprises three microporous pipes with stainless steel sleeves, and deionized water is supplied by a peristaltic pump (LIQUIPORT, KNF, Germany). The microporous pipes are made of waterproof and breathable expandedpolytetrafluoroethylene (e-PTFE, ID $0.24 \pm 0.007$; Wall $0.0296 \pm 0.005$; Density $0.65 \pm 0.15$ inch). To provide sufficient water vapor diffusion, the porosity was controlled to up to $80 \%$. The working conditions of supersaturated condensation growth control unit mainly included three parts: (1) The deionized water was drawn from the deionized water unit by the adjustable speed pump and flows back to the deionized water circulation unit through the channel between the concentric stainless steel tube sleeves and the microporous pipe. Water vapor penetrated in the pipe because of its waterproof and breathable characteristics, so the inner wall of the microporous pipe was moist and a vapor-saturated environment was formed. (2) The atmospheric particles or standard particles generated in the laboratory were then introduced into the sample gas channel, and the sample gas flow with particles entered the sample gas channel and then entered the saturated vapor channel, which comprises the concentric stainless steel tube sleeves and the microporous pipe. The outer 
wall of the tube sleeve was enclosed by a semiconductor refrigerator and a flexible heater, and the pipe was divided into three sections to create the temperature gradient. Every two stages are connected by an insulating block. (3) The semiconductor refrigerator operated in the cooling mode, and the flexible heater operated in the heating mode. Water vapor diffused into the mixing flow through the microporous wall and forms a mixture of saturated water vapor flow when mixing flow into the first stage of saturated water vapor channel controlled by semiconductor refrigeration. The mixing flow temperature was then reduced. Heat and water vapor diffusion into the center of mixing flow from microporous wall then flowed into the secondary saturated water vapor channel controlled by the flexible heater. The temperature of the mixing air was gradually increased. Because the water vapor diffusion rate is higher than the thermal diffusion rate, water vapor partial pressure of the mixing flow is higher than saturated vapor pressure at any point in the secondary saturated water vapor channel. Particles in the mixing flow are consistently in a supersaturated environment, which promotes the particles growth.

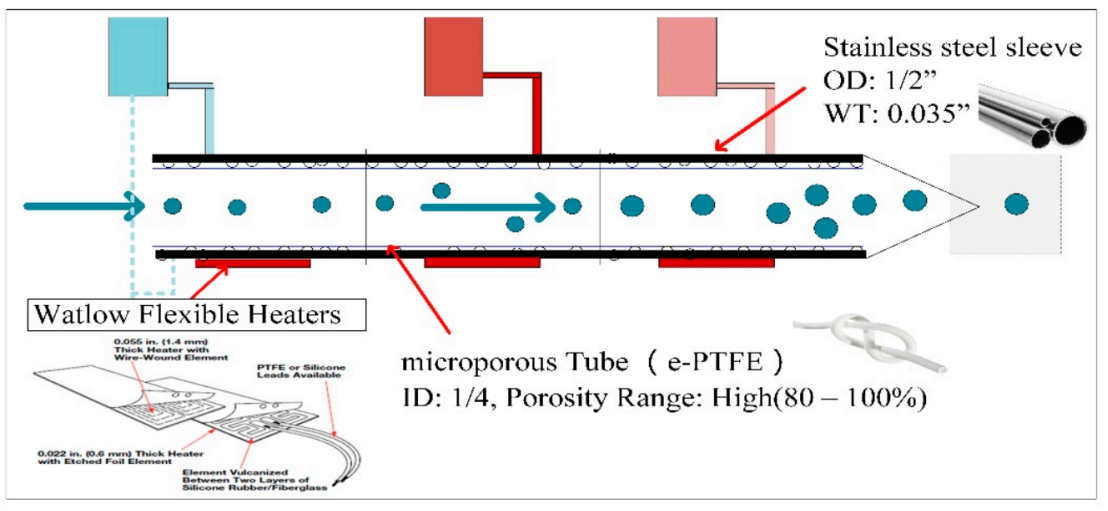

Figure 2. Schematic diagram of water-based supersaturated condensation growth control unit. The total length of the condensation growth control unit is $330 \mathrm{~mm}$, and the length of three stages are 154 $\mathrm{mm}, 76 \mathrm{~mm}$ and $100 \mathrm{~mm}$, respectively. Circles represent the flow path of particles, and deionized water circulation devices and arrows represent the flow direction of the deionized water.

All in all, particles were still in a water vapor supersaturation environment when the mixing flow proceeded through the third stage water vapor moderator channel. The water vapor content and temperature of out particle airflow can be adjusted by controlling the condensation growth control unit. The temperature gradient can be adjusted by controlling the conditioner and initiator temperatures [25].

\subsection{Activation Efficiency Calculation}

Activation efficiency is different as saturation variation, so the saturation calculation is required and the saturation cannot be measured directly. To investigate the spatial distribution of the saturation ratio of the designed condensation growth system and predict the minimum diameter of particles that are activated by condensation of water vapor, a two-dimensional axisymmetric model was developed in the COMSOL Multiphysics simulation software. Supersaturation, $\mathrm{S}$, is defined as the ratio of the partial pressure, $P_{v a}$ $(\mathrm{Pa})$, to its equilibrium vapor pressure, $P_{\text {sat }, T}(\mathrm{~Pa})$, at the temperature, $\mathrm{T}(\mathrm{K})$ as follows:

$$
\mathrm{S}=P_{v a} / P_{s a t, T}
$$

The Kelvin effect of thermodynamic principles describes the change in vapor pressure due to a curved liquid-vapor interface, such as the surface of a droplet. The vapor pressure at a convex curved surface is higher than that on a flat surface. The equilibrium vapor 
pressure required to activate the condensational growth of a smaller particle is higher because the larger particles have a flatter surface.

$$
D_{k, v a}=\left(4 \sigma_{s} M_{w}\right) /\left(\rho_{l} R_{g} T \ln S\right)
$$

where $\sigma_{s}(\mathrm{~N} / \mathrm{m}), M_{w}(\mathrm{~kg} / \mathrm{mol})$ and $\rho_{l}\left(\mathrm{~kg} / \mathrm{m}^{3}\right)$ are the surface tension, molecular weight, and the liquid density of the condensing species, respectively; $R_{g}(\mathrm{~J} /(\mathrm{mol} \cdot \mathrm{K}))$ is the universal gas constant; and T $(\mathrm{K})$ is the absolute temperature. $D_{k, v a}$ is a property of the condensing species equal to the diameter of a droplet in equilibrium with its vapor at saturation ratio $S$ and temperature $T$. The value is the same as the activation diameter for the case of a particle that is wetted by the condensing vapor but not soluble within it. Thus, a particle composed of a material that is not wetted by the condensing vapor will have a larger activation diameter than $D_{k, v a}$. For soluble particles, the equilibrium vapor pressure is reduced because of the condensate covering the particle surface, and the critical diameter required for growth is smaller than the Kelvin diameter.

Particle activation efficiency can be easily calculated by the ratio of the airflow in the maximum inclusion region of each Kelvin particle isoline and the total airflow. Because of the growth control unit is three-dimensional cylinder, the area covered by the maximum radial distance of each Kelvin diameter contour is solved initially, then multiplied by the average velocity of this region. In Figure 3, the contour map of velocity and Kelvin diameter distribution was calculated by COMSOL, and flow rate was set as $1.0 \mathrm{~L} / \mathrm{min}$. The velocity distribution is uniform under the function of laminar flow at the particle activation region. Using this approach, the average flow of this region was determined. Theoretical activation efficiency is the ratio of average flow of this region and total flow of the growth control system. In order to ignore effect of the actual temperature control accuracy, we selected $3{ }^{\circ} \mathrm{C}$ as the temperature difference of calculation activation efficiency. D50 of temperature difference $\left(44,47,50,53\right.$ and $\left.59^{\circ} \mathrm{C}\right)$ was obtained, and the D50 values were $3.82 \mathrm{~nm}, 3.41 \mathrm{~nm}, 2.85 \mathrm{~nm}, 2.66 \mathrm{~nm}$ and $2.39 \mathrm{~nm}$, respectively. Thereby, saturation can be gained if D50 is obtained.
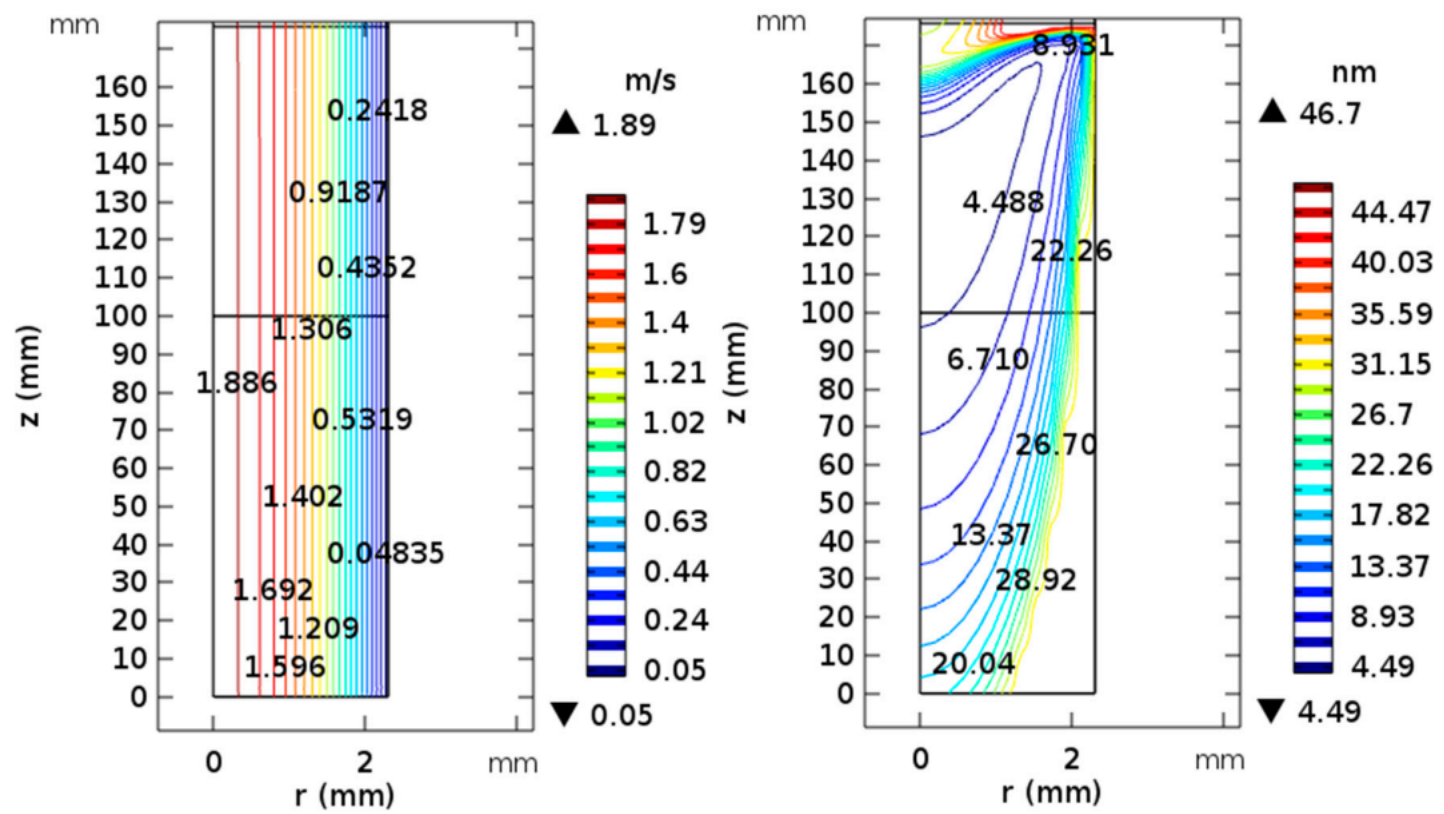

Figure 3. Contour map of velocity and Kelvin diameter distribution for laminar flow $\left(5^{\circ} \mathrm{C}, 95 \% \mathrm{RH}\right)$ entering a condensation growth control unit with temperature window $\left(20^{\circ} \mathrm{C}, 60^{\circ} \mathrm{C}\right)$. 


\subsection{Experimental Set-Up of Water-Based Supersaturation Control System Calibrtion}

Based on the above principle of activation efficiency calculation, to verify the reliability of the self-made water-based supersaturated condensation growth system, a calibration experiment was established (Figure 4). The calibration apparatus consisted of electrospray aerosol generator (model 3482 TSI, Shoreview, MN, USA) with standard particles range 2.5-150 nm, diffusion dryer (model 3062 TSI, Shoreview, MN, USA), differential mobility analyzers (DMA, model 3086 TSI, Shoreview, MN, USA), saturation condensation growth control system, condensation particle counter (CPC, model 3788 TSI, Shoreview, MN, USA) with detection limitation of $2.5 \mathrm{~nm}$ and optical particle counter. In the standard monodisperse particle generation and selection unit, the compressed air is generated when air is passed through a high-efficiency particulate-free air (HEPF), then particles flow through a diffusion dryer and then the built-in charger of the generator for charging. The DMA was included to obtain monodispersed particles of the selected size. The standard monodisperse particle number concentration is controlled as about $1000 / \mathrm{cm}^{3}$, because high concentration result in lack of water vapor. Monodispersed particles flow in two directions: some particles are sent to the CPC (model 3788 TSI, Shoreview, MN, USA), which counters the total particle number concentration of aerosol particles, and the other particles are sent to the saturation condensation growth control system with a detector (TSI, model 3321, Shoreview, MN, USA) to measure the activated particles at a certain supersaturation. As a result, particle numbers can be recorded when the sample flows before and after through the saturation condensation growth control system. The activated efficiency, defined as the ratio of the activated particle number concentration to the total particle number concentration at a specific supersaturation, is then determined [26].

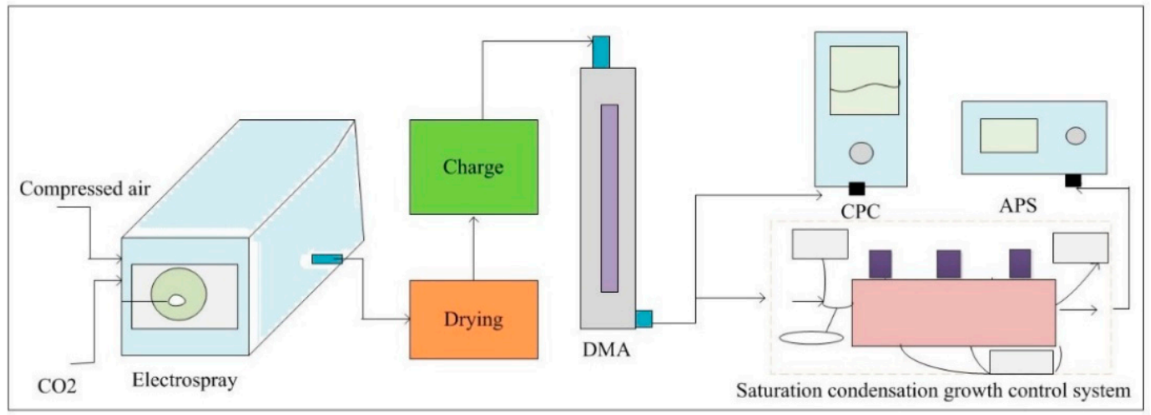

Figure 4. Schematic diagram of the experimental setup for the water-based supersaturated condensation growth control system calibration.

\section{Results and Discussions}

\subsection{Calculation Results of Water-Based Supersaturation Growth Control System}

The nanoparticles that flow through the saturation growth control system cannot be fully activated because the profiles of saturation, resulting in the counter and collection inaccuracy at the end of the growth control unit. Minimum activation cannot represent the performance of the supersaturated growth control unit, so an effective method is needed to calibrate the supersaturated growth control system, and the activation efficiency is an important index of calibration. Therefore, an activation efficiency curve was obtained for five different temperature differences (Figure 5). The activation efficiency was obtained by measuring the ratio between activated particle number and total particle number when the diameter of monodisperse particles changed from $2.5 \mathrm{~nm}$ to $9 \mathrm{~nm}$ for every temperature difference. Ammonium sulfate was selected as the particles to measure D50 reference the calibration method of cloud condensation nuclei counter $[27,28]$. The fitting curve is also shown in Figure 5. As the temperature difference increases, the activation efficiency curve moves to the left. The particle diameter with activation efficiency of $50 \%$ is defined as D50. The D50 at various temperature differences was obtained according to the measured fitting curve and had values of 4.05, 3.65, 3.10, 2.90 and $2.60 \mathrm{~nm}$ for the temperature differences of 
$44,47,50,53$ and $59^{\circ} \mathrm{C}$, respectively. The measurement result and theoretical calculation of D50 were compared, the maximum difference was $8.5 \%$. Therefore, D50 of measurement data was regarded as the activation size to inverse supersaturation.

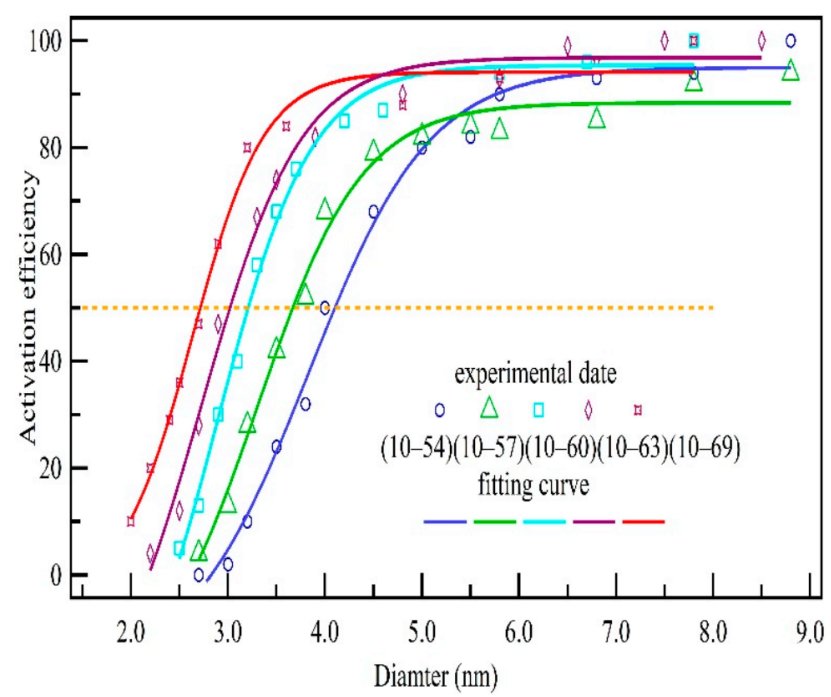

Figure 5. Experimental measurement of activation efficiency for various temperature differences.

Figure 6 illustrates the variation trend of measured D50 and correspondent saturation profile at five different temperature differences. To decrease the inaccuracy of inversed saturation calculated from the minimum activation size, saturation results that were shown in the figure were calculated from the D50 of measured data. The D50 changed from $4.05 \mathrm{~nm}$ to $2.60 \mathrm{~nm}$ as the temperature difference changed from 44 to $49^{\circ} \mathrm{C}$, and the D50 decreased slowly as the temperature difference increased. Saturation changed from 1.71 to 2.30 when the D50 changed from $4.05 \mathrm{~nm}$ to $2.60 \mathrm{~nm}$. The smaller the particle, the higher the saturation required for activation. Therefore, the calibration of the supersaturated growth control system was conducted for various temperature differences. Furthermore, the saturation changed from 1.71 to 2.30 as the temperature difference changed from $44^{\circ} \mathrm{C}$ to $59^{\circ} \mathrm{C}$, and the saturation of small temperature difference increased at a higher speed than that of the large temperature difference. The measured D50 data were then fit to a curve model to give the relation between saturation and temperature difference giving a fitting equation of $S=2.0492 \ln (T)-6.0507$, and the $R^{2}$ of fitting curve was 0.985 . The calibrated supersaturation ranged from 0.92 to 2.33 depending on the measured D50 when the temperature difference (between first two stage temperature) of the growth control system ranged from $30^{\circ} \mathrm{C}$ to $60^{\circ} \mathrm{C}$. The design requirement of $0.95-2.2$ and particle size less than $2.5 \mathrm{~nm}$ was reached. The temperature control accuracy is $0.1^{\circ} \mathrm{C}$; therefore, temperature control variation is usually set as $3^{\circ} \mathrm{C}$, so the influence of temperature control precision on temperature difference variation is less than 3.3\%. Lastly, the resolution is up to 0.14 . The following condensation growth experiment of various particle sizes and chemical components will be analyzed under different saturation conditions. 


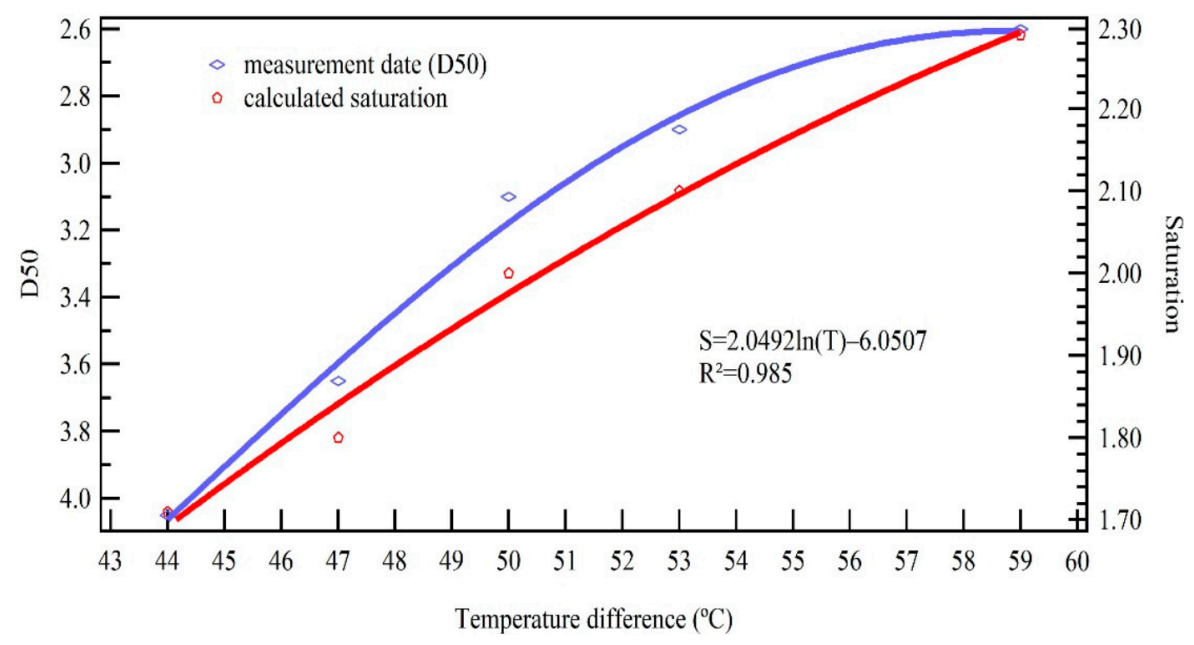

Figure 6. Diameter measurement of 50\% activation efficiency and corresponding saturation calculated from the measured D50 for various temperature differences.

\subsection{Stability Time of Condensation Growth Measurement System}

Stabilization time required to control different saturations is very important for growth characteristic measurement of particles at different saturations. Different saturations are controlled by adjusting the temperature difference. For the three stages operating the temperature condensation growth control unit, the temperature of first and third stage is controlled as $10^{\circ} \mathrm{C}$ and $25^{\circ} \mathrm{C}$, and we adjusted the second stage temperature to control saturation. The time required to stabilize the temperature in the second stage is considered as the time required to stabilize the saturation; with the second stage temperature variation $\pm 0.2^{\circ} \mathrm{C}$ (i.e., saturation variation \pm 0.1 ), we think the saturation stabilization. The experiment was done at room temperature of about $25^{\circ} \mathrm{C}$. Then the stabilization time was tested using this system. As shown in Figure 7, the required time of this system to reach a certain saturation was measured. The results are the average value across 20 times of measurement, and the indoor temperature is about $20^{\circ} \mathrm{C}$. Stability time becomes longer as the saturation increase. The stabilization time takes about $6 \mathrm{~min}$ go through seven saturation values from 0.92 to 2.33 saturation. This is helpful to measure condensation growth time at different saturations in a short time. In particular, the system reached the stabilization requirement after about $80 \mathrm{~s}$ at $92-101 \% \mathrm{RH}$ at $20^{\circ} \mathrm{C}$ room temperature. This is excellent compared with the hygroscopic growth system and can be a combined measurement with the hygroscopic growth system. The temperature fluctuation is about $\pm 0.3{ }^{\circ} \mathrm{C}$ at a steady saturation control situation, so the saturation control deviation of the system no more than 0.06 .

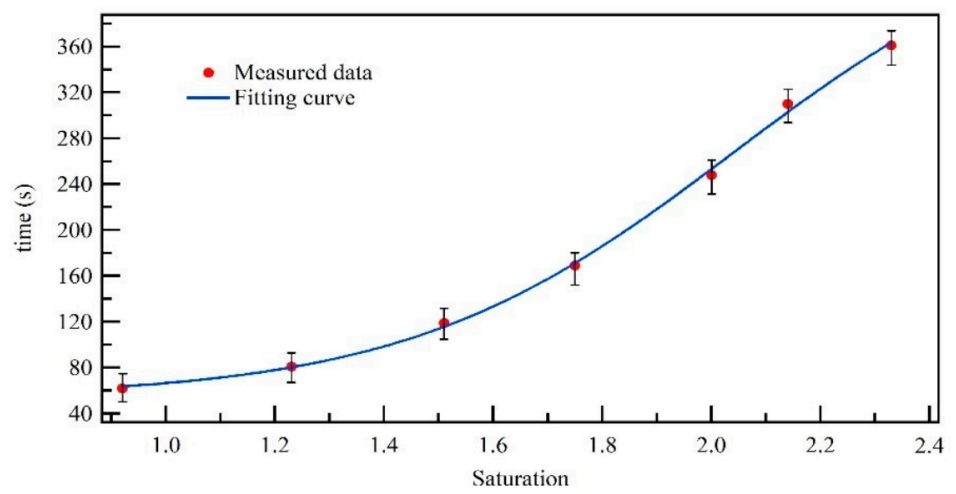

Figure 7. The time required to reach steady saturation for different saturations. 


\subsection{Measurement of Monodisperse Standard Particles for Different Supersaturated Condensation Growth Control Conditions}

This paper selected two respresentative compounds for preliminary measurement $[29,30]$. AS was selected as a representative inorganic salt because it is a dominant compound of the submicron aerosol mass present in the atmosphere and is an efficient scatterer of solar radiation. Glucose is a representative neutral organic compound and often occurs in the process of biomass combustion, which is an important compound of organic aerosols. Particle diameter of $80 \mathrm{~nm}$ and $150 \mathrm{~nm}$ were selected because the surface morphology of particles below and above $100 \mathrm{~nm}$ may be different. The chemical compounds (i.e., Ammonium sulfate and glucose) used were produced by Aladdin Reagent Inc. (reagent grade, $99.8 \%$ purity). The chemicals were individually dissolved in ultra-pure water (Direct-Q3, Millipore, Ramsey, MN, USA) to obtain a concentration of $1.0 \mathrm{~g} / \mathrm{L}$. Mixtures of AS and glucose were prepared by mixing the above solutions according to the solute mass ratio of $4: 1$ and 1:4.

Standard monodisperse particles of different sizes, chemical components and high supersaturation were tested. The standard monodisperse particle number concentration is controlled as about $1000 / \mathrm{cm}^{3}$. Compared with hygroscopic growth at high humidity, the particle size increased significantly. This proved the importance of ultrafine particles activation and growth to formed additional cloud droplet (Fan. et al.) [6]. The growth results (Figure 8a) indicate that particle increase in size increased with the supersaturation level, but the growth rate slowed slightly at the higher levels. This may be due to the increase in water vapor concentration as saturation increases. Moreover, the surface area of the particle increases as the particle size increases, and thus each particle requires more water vapor to grow to the same diameter, resulting in a lower growth rate. For AS particles, particles of $30 \mathrm{~nm}, 50 \mathrm{~nm}$ and $80 \mathrm{~nm}$ increased to a similar size at same saturation, with the size difference within $7.4 \%$. The small size difference of initial particle size and the similar condensation growth ability of same chemical compositions may explain this finding.

Figure $8 \mathrm{~b}$ shows that the standard particles with different particle sizes containing the same compound condensed to a similar size. Moreover, the standard particles of the inorganic AS compound increased more than those of the organic glucose; the increase in size for glucose was $13.4 \%-30.2 \%$ higher than that of AS. This might relate to the aging and the shape and crystallinity of organic molecules and the properties of inorganic particles [31].

Condensation growth performance is affected by the chemical composition of the mixture; different proportions of glucose and AS provide different growth characteristics. As shown in Figure 9, the increase in size increased with the increase of saturation, and the increase in size decreased about $15.9-25.0 \%$ with the increase of the glucose ratio. This presented the same conclusion with hygroscopic growth. This could be because of non-ideality effects in the mixed solution droplet and surface tension variation. Previous studies have shown that organic matter would forms dots or coating on the surface of particles depending on how much organic matter is present [32-34]. This is because the glass glucose coating on the surface of AS may have hindered the growth of mixed monodisperse standard particles during this process. 

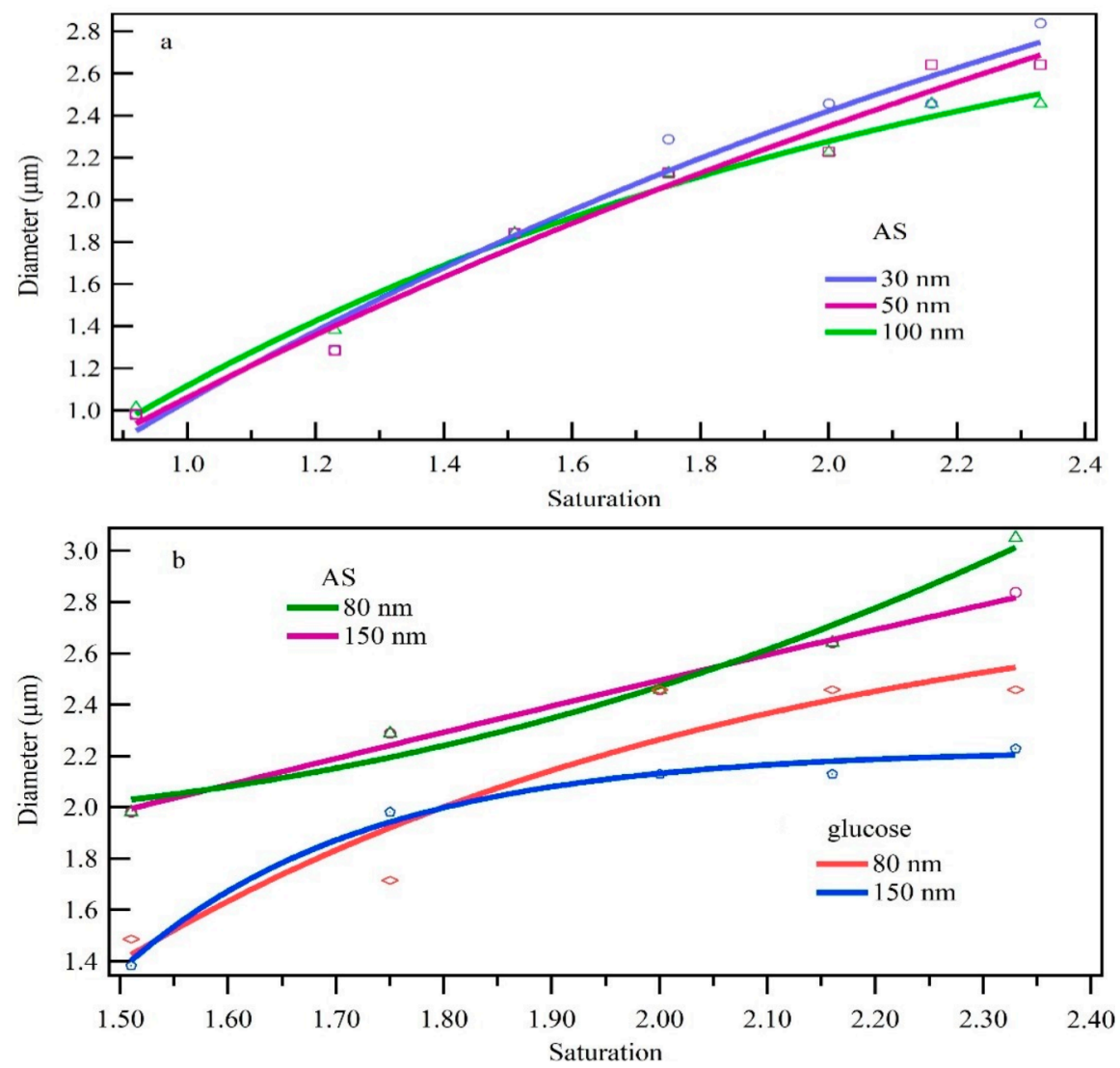

Figure 8. Condensation growth of standard particles with (a) different particle sizes and (b) different chemical components under different saturation conditions.

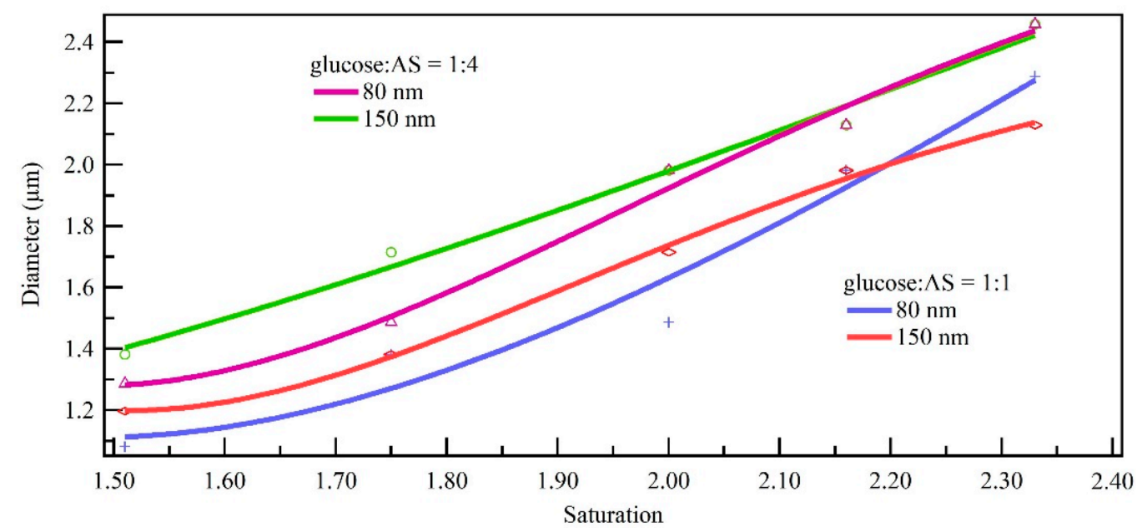

Figure 9. Growth result comparison of mixed component for monodisperse standard particles (80 $\mathrm{nm}$ and $150 \mathrm{~nm}$ ) under different saturation conditions.

\section{Conclusions}

In this study, a supersaturated condensation growth control system with adjustable supersaturation was designed to measure the growth performance of standard monodisperse particles and atmospheric particles under different saturation levels. The key results were as follows:

1. The calibrated supersaturation had a wide dynamic range from 0.92 to 2.33 or higher depending on the measured D50, and it meets the measurement requirement of 0.952.2. The resolution was up to 0.14 , the stabilization time about $6 \mathrm{~min}$ and even $80 \mathrm{~s}$ for saturation 0.92-1.01. This helped to control saturation rapidly, and the control deviation of saturation was no more than 0.06 . Moreover, a higher saturation can be 
achieved by adjusting the temperature difference. Thus, the constructed condensation growth system can be combined with a humidity control system to measure the growth factor over a wide humidity range (10-233\%).

2. A condensation growth experiment was conducted for monodisperse standard particles of different chemical components and different sizes under different saturation conditions. Compared with hygroscopic growth at high humidity, the particle size increased significantly. This proved the importance of ultrafine particles activation and growth to form additional cloud droplet. The condensation growth result of single-component standard particles showed that particles increase in size as the saturation increases; for AS particles, condensation growth medium size of $30 \mathrm{~nm}, 50 \mathrm{~nm}$ and $80 \mathrm{~nm}$ increased to similar sizes at the same saturation level, with a difference within $13.4 \%$. AS particles grew to a size larger than glucose particles when the same size particles passed through the growth control system, and the increase in size for AS increased $13.4-30.2 \%$ relative to that of glucose.

3. For mixed-component particles, the increase in size for particles increased with the increase of saturation, and with the increase of glucose ratio, the increase in size decreased about 15.9-25.0\%. Hygroscopic organic compounds inhibited the growth of inorganic compounds for mixed-component particles.

This research focused on the design of saturation growth control system with a wide dynamically saturation and preliminary experiment of different particle sizes and different chemical components. The establishment of a dynamic analysis system for the condensation growth of atmospheric ultrafine particles, combined with theoretical model, experimental simulation and field observation is necessary to realize accurate online measurement and mechanism analysis of the dynamic process of atmospheric particle condensation growth.

Author Contributions: J.B.: study design, data processing, and writing; H.G.: method design and reviewing; X.W.: analysis and reviewing; T.Y.: analysis and reviewing; Z.X.: provided recommendations on result; J.W.: reviewing; J.L.: analytical protocol design and reviewing. All authors have read and agreed to the published version of the manuscript.

Funding: Experiment were given grant support by the Natural Science Foundation of China (No. 91544218, 41905028), the National Key Research and Development Program of China (No. 2016YFC0201001), the Science and Technological Fund of Anhui Province (1808085J19, 1908085MD114, 2008085MD116) and the CASHIPS Director's Fund (YZJJ2018QN5, YZJJ2019QN1).

Conflicts of Interest: The authors declare no conflict of interest.

\section{References}

1. Pandis, S.N.; Seinfeld, J.H.; Pilinis, C. The smog-fog-smog cycle and acid deposition. J. Geophys. Res. Atmos. 1990, 95, 18489-18500. [CrossRef]

2. Tang, G.Q.; Zhao, P.S.; Wang, Y.H.; Gao, W.K.; Cheng, M.T.; Xin, J.Y.; Li, X.; Wang, Y.S. Mortality and air pollution in Beijing: The long-term relationship. Atmos. Environ. 2017, 150, 238-243. [CrossRef]

3. Kerminen, V.M.; Paramonov, M.; Anttila, T.; Riipinen, I.; Fountoukis, C.; Korhonen, H.; Asmi, E.; Laakso, L.; Lihavainen, H.; Swietlicki, E.; et al. Cloud condensation nuclei production associated with atmospheric nucleation: A synthesis based on existing literature and new results. Atmos. Chem. Phys. 2012, 12, 12037-12059. [CrossRef]

4. Kulmala, M.; Pirjola, U.; Makela, J.M. Stable sulphate clusters as a source of new atmospheric particles. Nature 2000, 404, 66-69. [CrossRef] [PubMed]

5. Zhang, R.; Khalizov, A.; Wang, L.; Hu, M.; Xu, W. Nucleation and growth of nanoparticles in the atmosphere. Chem. Rev. 2012, 112, 1957-2011. [CrossRef] [PubMed]

6. $\quad$ Fan, J.W.; Rosenfeld, D.; Zhang, Y.W.; Giangrande, S.E.; Li, Z.Q.; Machado, L.A.T.; Martin, S.T.; Yang, Y.; Wang, J.; Artaxo, P.; et al. Substantial convection and precipitation enhancements by ultrafine aerosol particles. Science 2018, 359, 411-418. [CrossRef] [PubMed]

7. Agarwal, J.K.; Sem, G.J. Continuous-flow, single-particle-counting condensation nucleus counter. J. Aerosol Sci. 1980, 11, 343-357. [CrossRef]

8. Kuang, C.A.; Chen, M.D.; McMurry, P.H.; Wang, J. Modification of laminar flow ultrafine condensation particle counters for the enhanced detection of $1 \mathrm{~nm}$ condensation nuclei. Aerosol Sci. Technol. 2012, 46, 309-315. [CrossRef]

9. Kulmala, M.; Laakso, L.; Lehtinen, K.E.J.; Riipinen, I.; Dal Maso, M.; Anttila, T.; Kerminen, V.M.; Horrak, U.; Vana, M.; Tammet, H. Initial steps of aerosol growth. Atmos. Chem. Phys. 2004, 4, 2553-2560. [CrossRef] 
10. Stolzenburg, M.R.; McMurry, P.H. An ultrafine aerosol condensation nucleus counter. Aerosol Sci. Technol. 1991, 14, 48-65. [CrossRef]

11. Duan, J.Y.; Wang, Y.Y.; Xie, X.; Li, M.; Tao, J.; Wu, Y.F.; Cheng, T.T.; Zhang, R.J.; Liu, Y.H.; Li, X.; et al. Influence of pollutants on activity of aerosol cloud condensation nuclei $(\mathrm{CCN})$ during pollution and post-rain periods in Guangzhou, southern China. Sci. Total Environ. 2018, 642, 1008-1019. [CrossRef]

12. Chang, D.Y.; Lelieveld, J.; Tost, H.; Steil, B.; Pozzer, A.; Yoon, J. Aerosol physicochemical effects on CCN activation simulated with the chemistry-climate model EMAC. Atmos. Environ. 2017, 162, 127-140. [CrossRef]

13. Nenes, A.; Chuang, P.Y.; Flagan, R.C.; Seinfeld, J.H. A theoretical analysis of cloud condensation nucleus (CCN) instruments. J. Geophys. Res. Atmos. 2001, 106, 3449-3474. [CrossRef]

14. Fukuta, N.; Saxena, V.K. Horizontal thermal-gradient cloud condensation nucleus spectrometer. J. Appl. Meteorol. 1979, 18, 1352-1362. [CrossRef]

15. Hudson, J.G. An instantaneous CCN spectrometer. J. Atmos. Ocean. Technol. 1989, 6, 1055-1065. [CrossRef]

16. Mordas, G.; Sipila, M.; Kulmala, M. Nanometer particle detection by the condensation particle counter UF-02proto. Aerosol Sci. Technol. 2008, 42, 521-527. [CrossRef]

17. Stolzenburg, M.R.; McMurry, P.H. Equations governing single and tandem DMA configurations and a new lognormal approximation to the transfer function. Aerosol Sci. Technol. 2008, 42, 421-432. [CrossRef]

18. Michel Flores, J.; Bar-Or, R.Z.; Bluvshtein, N.; Abo-Riziq, A.; Kostinski, A.; Borrmann, S.; Koren, I.; Koren, I.; Rudich, Y. Absorbing aerosols at high relative humidity: Linking hygroscopic growth to optical properties. Atmos. Chem. Phys. 2012, 12, 5511-5521. [CrossRef]

19. Kulmala, M.; Riipinen, I.; Sipila, M.; Manninen, H.E.; Petaja, T.; Junninen, H.; Dal Maso, M.; Mordas, G.; Mirme, A.; Vana, M.; et al. Toward direct measurement of atmospheric nucleation. Science 2007, 318, 89-92. [CrossRef]

20. Villani, P.; Picard, D.; Michaud, V.; Laj, P.; Wiedensohler, A. Design and Validation of a volatility hygroscopic tandem differential mobility analyzer (VH-TDMA) to characterize the relationships between the thermal and hygroscopic properties of atmospheric aerosol particles. Aerosol Sci. Technol. 2008, 42, 729-741. [CrossRef]

21. Lei, T.; Ma, N.; Hong, J.; Tuch, T.; Wang, X.; Wang, Z.; Pöhlker, M.; Ge, M.; Wang, W.; Mikhailov, E.; et al. Nano-hygroscopicity tandem differential mobility analyzer (nano-HTDMA) for investigating hygroscopic properties of sub-10 nm aerosol nanoparticles. Atmos. Meas. Tech. 2020, 13, 5551-5567. [CrossRef]

22. Duplissy, J.; Gysel, M.; Sjogren, S.; Meyer, N.; Good, N.; Kammermann, L.; Michaud, V.; Weigel, R.; dos Santos, S.M.; Gruening, C.; et al. Intercomparison study of six HTDMAs: Results and recommendations. Atmos. Meas. Tech. 2009, 2, 363-378. [CrossRef]

23. Kupc, A.; Bischof, O.; Tritscher, T.; Beeston, M.; Krinke, T.; Wagner, P.E. Laboratory characterization of a new nano-water-based CPC 3788 and performance comparison to an ultrafine butanol-based CPC 3776. Aerosol Sci. Technol. 2013, 47, 183-191. [CrossRef]

24. Keller, A.; Tritscher, T.; Burtscher, H. Performance of water-based CPC 3788 for particles from a propane-flame soot-generator operated with rich fuel/air mixtures. J. Aerosol Sci. 2013, 60, 67-72. [CrossRef]

25. Bian, J.; Gui, H.; Xie, Z.; Yu, T.; Wei, X.; Wang, W.; Liu, J. Simulation of three-stage operating temperature for supersaturation water-based condensational growth tube. J. Environ. Sci. China 2020, 90, 275-285. [CrossRef]

26. Hering, S.V.; Stolzenburg, M.R. A method for particle size amplification by water condensation in a laminar, thermally diffusive flow. Aerosol Sci. Technol. 2005, 39, 428-436. [CrossRef]

27. Ma, N.; Zhao, C.; Deng, Z.; Tao, J.; Yu, R.; Chen, J.; Bian, Y. A modified method for calibrating the supersaturations in DMT cloud condensation nuclei counter. Acta Sci. Nat. Univ. Pekin. 2014, 50, 805-811.

28. Rose, D.; Gunthe, S.S.; Mikhailov, E.; Frank, G.P.; Dusek, U.; Andreae, M.O.; Poeschl, U. Calibration and measurement uncertainties of a continuous-flow cloud condensation nuclei counter (DMT-CCNC): CCN activation of ammonium sulfate and sodium chloride aerosol particles in theory and experiment. Atmos. Chem. Phys. 2008, 8, 1153-1179. [CrossRef]

29. Denjean, C.; Formenti, P.; Picquet-Varrault, B.; Katrib, Y.; Pangui, E.; Zapf, P.; Doussin, J.F. A new experimental approach to study the hygroscopic and optical properties of aerosols: Application to ammonium sulfate particles. Atmos. Meas. Tech. 2014, 7, 183-197. [CrossRef]

30. Mochida, M.; Kawamura, K. Hygroscopic properties of levoglucosan and related organic compounds characteristic to biomass burning aerosol particles. J. Geophys. Res. Atmos. 2004, 109. [CrossRef]

31. Zhao, Y.; Liu, Y.C.; Ma, J.Z.; Ma, Q.X.; He, H. Heterogeneous reaction of SO2 with soot: The roles of relative humidity and surface composition of soot in surface sulfate formation. Atmos. Environ. 2017, 152, 465-476. [CrossRef]

32. Petters, S.S.; Petters, M.D. Surfactant effect on cloud condensation nuclei for two-component internally mixed aerosols. J. Geophys. Res. Atmos. 2016, 121, 1878-1895. [CrossRef]

33. Kreidenweis, S.M.; Remer, L.A.; Bruintjes, R.; Dubovik, O. Smoke aerosol from biomass burning in Mexico: Hygroscopic smoke optical model. J. Geophys. Res. Atmos. 2001, 106, 4831-4844. [CrossRef]

34. Kuai, Y.; Xie, Z.; Chen, J.; Gui, H.; Xu, L.; Kuang, C.; Wang, P.; Liu, X.; Liu, J.; Lakowicz, J.R.; et al. Real-time measurement of the hygroscopic growth dynamics of single aerosol nanoparticles with bloch surface wave microscopy. ACS Nano 2020, 14, 9136-9144. [CrossRef] 